\title{
Comparison of frequency of depression and sleep quality in patients with Type 2 Diabetes mellitus with controls
}

\author{
Research Article
}

\section{Parisa Ghasemi Noghabi ${ }^{1}$, Sahar Ghareh ${ }^{2 *}$, Maryam Javanbakht ${ }^{3}$}

1. Clinical Research Development unit,Bohlool Hospital, Gonabad University of Medical Sciences, Gonabad, Iran

2. Department of Endocrinology, Mashhad Branch, Islamic Azad University, Mashhad, Iran

3. Department of Psychiatry, Mashhad Branch, Islamic Azad University, Mashhad, Iran

\begin{abstract}
Diabetes mellitus with its high prevalence and related hygienic problems is one of the most important worldwide burdens that can also cause mental and psychological side effects. The disease complications, chronic progress, treatment costs and social problems are among the issues that can affect the patients' cognitive function and cause depression and sleep disorders. Failure to diagnose and treatment of such issues causes a poor prognosis and increases the risk of death. High prevalence of sleep disorders in diabetic adults and its association with depression and glucose metabolism encouraged us to conduct a study to compare the frequency of depression and sleep disorders in type-2 diabetic patients with non-diabetics. Methodology In a prospective case-control study design, considering the inclusion and exclusion criteria, 64 diabetic patients from 22 Bahman Hospital and 86 nondiabetic individuals as the matched group, were enrolled in the study during the years 2013 to 2014. To gather the data, Pittsburg sleep quality index and Hamilton depression rating scale was used. Results Sleep quality disorders and depression are more common in diabetic patients. In diabetic patients, percentage of depression and sleep quality disorders was $78.1,68$, and in non-diabetics, it was $50 \%$ and $36 \%$, respectively. This study showed significant relationship between sleep quality disorders and depression between the two groups of participants. No significant relationship was found regarding control blood sugar, type of treatment and the amount of time a person is exposed to the disease and incidence of depression and sleeping problems. Conclusion Regarding the high prevalence of depression and sleep disorders in diabetic patients, it is necessary to diagnose depression and sleep disorders.
\end{abstract}

Keywords: Type-2 diabetes mellitus, depression, sleep disorders.

\section{Introduction}

Diabetes Mellitus as a non- Contagious chronic disease with extensive complication and high prevalence is significantly important. Diabetes mellitus type 2 (DMT2) Includes a heterogeneous group of disorders characterized by varying degrees of insulin resistance, insulin secretion and glucose secretion. The global prevalence of diabetes mellitus has increased dramatically over the past two decades, from around 30 million cases in 1985 to 285 million cases in 2010. In 2010, the prevalence of diabetes mellitus in 10 countries with the highest prevalence was from $11.6 \%$ to $30.9 \%$. Glucose tolerance can be evaluated using fasting plasma glucose (FPG), oral glucose tolerance test (OGTT) or hemoglobin A1C levels (1). Patients with diabetes often have other problems. A number of recent studies have reported the association of sleep disorder in diabetic patients (2). About one third of adults in the world suffer from sleep disorders. Also aging and incidence of chronic diseases exacerbate that, which increases by as much as $69 \%(3,4)$. The prevalence of

*Corresponding Author:

\section{Sahar Ghareh}

Department of endocrinology,

Mashhad Branch,

Islamic Azad University,

Mashhad, Iran

Email: gareh.s@gmail.com sleep disorders is high in diabetic patients (5). Studies mentioned that depth of sleep affects carbohydrate metabolism or endocrine system. Insomnia decreases with insulin resistance while insulin resistance decreases during sleep. These results indicate that sleeplessness and low sleep quality is associated with glucose metabolism (6). Depression is the most common emotional disorder and the greatest mental illness of the present century. Epidemiological evidence suggests that at any moment, between $15 \%$ and $20 \%$ of the adult population of the community may exhibit various signs and symptoms of severe depression. Depression is one of the most common psychiatric disorders in diabetic patients .Studies have shown that prevalence of depression in diabetic patients is $61.3 \%$ (7). Depression significantly increases the risk of death among people with diabetes. Sleep disorders are associated with depression so that in the absence of sleep disorders, the diagnosis of depression is skeptical; 60$80 \%$ of depressed people are afflicted with insomnia (8).Diabetics have a shorter sleep time than normal sleep. Lack of sleep can have detrimental effects on the health and well-being of the patient (9), Therefore, psychological factors such as sleep disturbance and depression in these patients should be identified and treated. Regarding the prevalence and effect of depression and sleep disturbance in diabetic patients and its effect on mental health, glucose metabolism and prognosis of patients, the present study was conducted to compare the frequency of depression and sleep disturbance in diabetic patients with non- diabetic patients. 


\section{Materials and Method}

This cohort study was performed on patients with DMT2 who referred to diabetes clinic of 22 Bahman Hospital in 2013-2014 in Mashhad, Iran. The diagnosis criteria of DMT2 which was done by the American Diabetes Association (ADA) are as follows: Fasting Plasma Glucose level $\geq 126$ mg / dl, Symptoms of diabetes plus plasma glucose concentration $\geq 200 \mathrm{mg} / \mathrm{dl}$ in randomized samples, or A1C hemoglobin $\geq 6.5$, or two-hour plasma glucose $\geq 200 \mathrm{mg} / \mathrm{dl}$ during oral glucose tolerance test .The sampling method was convenience.

After considering the inclusion and exclusion criteria the consent of the subjects was taken in writing form. The Pittsburgh sleep quality questionnaire and the checklist containing the name, age, sex, height, weight, degree of education (cycle-diploma-university) Marital status (single married - marriage leading to divorce), number of children, duration of diabetes, type of treatment (oral-intestinal), FBS and HBA1C were completed by the individual. The nurse adjusted the Hamilton Depression questionnaire by interviewing the individual.

\section{Eligibility criteria}

The participants of this study were recruited from; Patients with DMT2 and healthy subjects over 18 years old; who had at least a cycle of education and signed the consent form to participate in our study. Exclusion criteria were as follows: Patients with DMT2 with severe psychiatric disorders such as psychosis; a history of admission to psychiatric section; seizure and epilepsy and severe head trauma; and also, who taking psychiatric medications currently, severe stress in the last six months, night work; excessive alcohol abuse; a history of endocrine disorder; history of connective tissue disease; pregnant and breastfeeding women and who did not agree to participate in this study.

\section{Data collection}

Several methods currently exist for the measurement of sleep quality; we used Pittsburgh Sleep Quality Index [PSQI]. (10) This questionnaire is a standard international tool for monitoring sleep quality. This index examines attitudes about sleep quality over the past four weeks. The questionnaire consists of seven sub-indicators including general sleep, sleep latency, sleep rate, adequacy of sleep, sleep disorders, hypnotics and daily dysfunction. The total score of seven scales indicates the total score of individuals' sleep. The respondent answers the questions based on their sleep status. Then each of the sub-indicators is graded between zero (best condition) and three (worst), therefore the total score of the questionnaire is between zero and 21 the overall score $>5$, means poor sleep quality. Many researchers have utilized Hamilton questionnaire to measure Depression.(11) This scale has 21 items. After an interview with patient, the interviewer scores each item on a five-part or three-part scale. The Hamilton questionnaire has 21 items of depression and each character has three to five options, which range from 0 to 2 or 0 to 4 , graded by severity. The person's score in the Hamilton Depression test are divided to 4 ranges which included: 8-13 (mild depression), 14-18 (moderate depression), 19-22 (severe depression) and 23 or more that indicated the severe depression. These indexes were selected for their reliability and validity.

\section{Statistical analysis}

To evaluate the data, Kolmogorov-Smirnov test was used with Lilliefors correction. Parametric methods such as $\mathrm{t}$ - test and variance analysis were used for normal distribution and Spearman correlation, Mann-Whitney and KruskalWallis tests are used for abnormal distribution. Logistic regression was used for results simultaneous analysis. Analyses were carried out using IBM-SPSS 20 version and the significance of tests considered less than $5 \%$.

\section{Results}

In this study, we conducted 64 patients with type II diabetes mellitus (29male (45.3\%), 35 female (54.7\%)) and 86 non-diabetic patients (45male $(52.3 \%), 41$ female $(47.7 \%))$.

The mean depression (14.22 \pm 7.94$)$ and mean sleep disorder $(6.77 \pm 3.62)$ in diabetic patients is significantly higher than the control group $(8.57 \pm 5.54,4.38 \pm 2.32$ respectively). $(\mathrm{p}<0.05)$

The average rate of depression and sleep disorder in diabetic patients who use oral and insulin therapy $(12.6 \pm 8.02,5.80 \pm 2.59$ respectively) is lower than the patients who use oral $(14.20 \pm 8.50,6.85 \pm 3.56$ respectively) and patients who are insulin-dependent $(14.68 \pm 6.98,6.84 \pm 4.10$ respectively), but this difference is not statistically significant. $(\mathrm{p}>0.05)$

The mean level of depression and sleep disorder in diabetic patients with high HBA1C (13.67 $\pm 7.21,6.6 \pm 3.69$ respectively) is significantly lower than in diabetic patients with normal HBA1C (16 $\pm 9.68,7.67 \pm 3.41$ respectively), but this difference is not statistically significant. $(\mathrm{p}>0.05)$

The mean level of depression and sleep disorder in diabetic patients with normal FBS (13.2 $\pm 8.21,7.05 \pm 3.85$ respectively) is significantly lower than diabetic patients with abnormal FBS (14.93 $\pm 7.94,6.85 \pm 3.55$ respectively), but this difference is not statistically significant. $(\mathrm{p}>0.05)$

The mean depression and sleep disorder in the control group over 50 years was significantly lower in diabetic patients over 50 years. $(\mathrm{p}<0.05)$ And In control group with the age less than 50 years, no significant difference was found between the two groups in terms of depression. $(\mathrm{p}>0.05)$

In the male group, the mean of depression and sleep disorder in patients $(12.38 \pm 6.16,6.03 \pm 3.11$ respectively) was significantly higher than the control group (7.31 \pm 3.94 , $4.2 \pm 2.12$ respectively). $(\mathrm{p}<0.05)$ Also in the female group, the mean of depression and sleep disorder in patients (15.74 $\pm 8.96, \quad 7.37 \pm 3.94$ respectively) was significantly higher than the control group $(9.95 \pm 6.66,4.59 \pm 2.54$ respectively). $(\mathrm{p}<0.05)$

In the group with moderate weights, the mean rate of depression was significantly higher in patients (13.47 \pm 7.21$)$ than in the control group $(8.52 \pm 5.85) .(p<0.05)$ Also in the overweight group, the mean range of depression and sleep disorder in patients $(14.29 \pm 7.87,7.29 \pm 3.62$ respectively) was significantly higher than the control group $(8.54 \pm 5.09$, $4.66 \pm 1.97$ respectively). $(\mathrm{p}<0.05)$ and we can consider that in the fat group the mean range of sleep disorder in patients (6.56 \pm 3.67$)$ was significantly higher than the control group $(3.27 \pm 1.35) .(\mathrm{p}<0.05)$

*Because only one of the controls and patients are underweight, so there is no way to test the comparison between the two groups. 
Parisa Ghasemi Noghabi et.al., Frequency of depression and sleep quality in diabetes patients

Table 1: Depression and sleep disorder status in diabetics and control group.

\begin{tabular}{|c|c|c|}
\hline Variables & Case & Control \\
\hline Sleep Disorder & $6.77 \pm 3.62$ & $4.38 \pm 2.32$ \\
\hline Depression & $14.22 \pm 7.94$ & $8.57 \pm 5.54$ \\
\hline
\end{tabular}

Table 2: Comparison of depression and sleep disorder in diabetics and control group

\begin{tabular}{|c|c|c|c|c|c|c|}
\hline Variables & & & Depression & P value & Sleep Disorder & P value \\
\hline & $O A D^{*}$ & & $14.20 \pm 8.50$ & & $6.85 \pm 3.56$ & \\
\hline $\begin{array}{l}\text { Type of } \\
\text { treatment }\end{array}$ & $\begin{array}{l}\text { Insulin } \\
O A D+\text { Insulin }\end{array}$ & & $\begin{array}{l}14.68 \pm 6.98 \\
12.60 \pm 8.02\end{array}$ & 0.876 & $\begin{array}{l}6.84 \pm 4.10 \\
5.80 \pm 2.59\end{array}$ & 0.837 \\
\hline HBA1C & $\begin{array}{l}\text { Normal } \\
\text { High }\end{array}$ & & $\begin{array}{l}16.00 \pm 9.68 \\
13.67 \pm 7.21\end{array}$ & 0.305 & $\begin{array}{l}7.67 \pm 3.41 \\
6.60 \pm 3.69\end{array}$ & 0.15 \\
\hline FBS & $\begin{array}{l}\text { Normal } \\
\text { High }\end{array}$ & & $\begin{array}{l}13.20 \pm 8.21 \\
14.93 \pm 7.94\end{array}$ & 0.414 & $\begin{array}{l}7.05 \pm 3.85 \\
6.85 \pm 3.55\end{array}$ & 0.811 \\
\hline Age ${ }^{* T}$ & $\begin{array}{l}\leq 50 \\
50 \leq \text { age } \leq 60 \\
\geq 60\end{array}$ & $\begin{array}{l}\text { Control } \\
\text { Case } \\
\text { Control } \\
\text { Case } \\
\text { Control } \\
\text { Case }\end{array}$ & $\begin{array}{l}9.04 \pm 5.07 \\
12.07 \pm 5.47 \\
8.75 \pm 6.33 \\
15.88 \pm 8.73 \\
8.15 \pm 5.54 \\
13.76 \pm 8.19\end{array}$ & $\begin{array}{l}0.085 \\
0.004 \\
0.005\end{array}$ & $\begin{array}{l}4.89 \pm 2.22 \\
4.93 \pm 1.86 \\
3.80 \pm 1.24 \\
7.36 \pm 3.97 \\
4.33 \pm 2.75 \\
7.20 \pm 3.79\end{array}$ & $\begin{array}{l}0.796 \\
0.002 \\
0.001\end{array}$ \\
\hline Sex & $\begin{array}{l}\text { Men } \\
\text { Women }\end{array}$ & $\begin{array}{l}\text { Control } \\
\text { Case } \\
\text { Control } \\
\text { Case }\end{array}$ & $\begin{array}{l}7.31 \pm 3.94 \\
12.38 \pm 6.16 \\
9.95 \pm 6.66 \\
15.74 \pm 8.96\end{array}$ & $\begin{array}{l}0.0001 \\
0.002\end{array}$ & $\begin{array}{l}4.20 \pm 2.12 \\
6.03 \pm 3.11 \\
4.59 \pm 2.54 \\
7.37 \pm 3.94\end{array}$ & $\begin{array}{l}0.01 \\
0.001\end{array}$ \\
\hline BMI & $\begin{array}{l}\text { Under weight } \\
\text { Normal } \\
\text { Over weight } \\
\text { Fat }\end{array}$ & $\begin{array}{l}\text { Control } \\
\text { Case } \\
\text { Control } \\
\text { Case } \\
\text { Control } \\
\text { Case } \\
\text { Control } \\
\text { Case }\end{array}$ & $\begin{array}{l}4 \\
11 \\
8.52 \pm 5.85 \\
13.47 \pm 7.21 \\
8.54 \pm 5.09 \\
14 \pm 29 \pm 7.87 \\
9.27 \pm 6.69 \\
15.19 \pm 9.40\end{array}$ & $\begin{array}{l}0.009 \\
0.001 \\
0.085\end{array}$ & $\begin{array}{l}6 \\
4 \\
4.48 \pm 2.86 \\
6.21 \pm 3.78 \\
4.66 \pm 1.97 \\
7.29 \pm 3.62 \\
3.27 \pm 1.35 \\
5.56 \pm 3.67 \\
\end{array}$ & $\begin{array}{l}0.069 \\
0.001 \\
0.004\end{array}$ \\
\hline
\end{tabular}

Table3: Frequency of depression and sleep disorder in diabetic patients, based on a different variables

\begin{tabular}{|c|c|c|c|c|c|c|c|c|c|}
\hline \multirow[b]{2}{*}{ Items } & & & \multicolumn{5}{|c|}{ Depression } & \multicolumn{2}{|c|}{ Sleep } \\
\hline & & & Non & Mild & Moderate & Severe & $\begin{array}{c}\text { Very } \\
\text { Severe }\end{array}$ & Normal & Abnormal \\
\hline \multirow{3}{*}{$\begin{array}{c}\text { Duration of } \\
\text { disease }\end{array}$} & & $<10^{*}$ & 23.7 & 34.2 & 10.5 & 15.8 & 15.8 & 28.9 & 71.1 \\
\hline & & $10<x<20$ & 18.8 & 37.5 & 6.20 & 25.0 & 12.5 & 31.2 & 68.8 \\
\hline & & $20<$ & 14.3 & 14.3 & 28.6 & 28.6 & 14.3 & 28.6 & 71.4 \\
\hline \multirow{3}{*}{$\begin{array}{l}\text { Type of } \\
\text { treatment }\end{array}$} & & $\mathrm{OAD}^{* 1}$ & 22.5 & 35.0 & 10.0 & 17.5 & 15.0 & 30.0 & 70.0 \\
\hline & & Insulin & 15.8 & 31.6 & 15.8 & 21.1 & 15.8 & 31.6 & 68.4 \\
\hline & & $\mathrm{OAD} \pm$ Insulin & 40.0 & 20.0 & 0.0 & 40.0 & 0.0 & 40.0 & 60.0 \\
\hline \multirow{2}{*}{ HBAIC } & & Normal & 16.7 & 33.3 & 5.6 & 22.2 & 22.2 & 11.1 & 88.9 \\
\hline & & High & 23.3 & 32.6 & 14.0 & 18.6 & 11.6 & 37.2 & 62.8 \\
\hline \multirow{2}{*}{ FBS } & & Normal & 25.0 & 35.0 & 10.0 & 20.0 & 10.0 & 25.0 & 31.7 \\
\hline & & Abnormal & 19.5 & 31.7 & 12.2 & 19.5 & 17.1 & 75.0 & 68.3 \\
\hline \multirow{4}{*}{ Sex } & \multirow{2}{*}{ Men } & Control & 55.6 & 40.0 & 4.4 & 0.0 & 0.0 & 62.2 & 37.8 \\
\hline & & Case & 27.6 & 41.4 & 6.9 & 13.8 & 10.3 & 41.4 & 58.6 \\
\hline & \multirow{2}{*}{ Women } & Control & 43.9 & 29.3 & 14.6 & 2.4 & 9.8 & 65.9 & 34.1 \\
\hline & & Case & 17.1 & 25.7 & 14.3 & 25.7 & 17.1 & 22.9 & 77.1 \\
\hline \multirow{8}{*}{ BMI } & \multirow{2}{*}{$\begin{array}{r}\text { Under } \\
\text { Weight }\end{array}$} & Control & 100 & 0.0 & & & & 100 & 0.0 \\
\hline & & Case & 0.0 & 100 & & & & 0.0 & 100 \\
\hline & \multirow{2}{*}{ Normal } & Control & 54.5 & 30.3 & 9.1 & 0.0 & 6.1 & 60.6 & 39.4 \\
\hline & & Case & 21.1 & 42.1 & 0.0 & 26.3 & 10.5 & 47.4 & 52.6 \\
\hline & \multirow{2}{*}{$\begin{array}{c}\text { Over } \\
\text { Weight }\end{array}$} & Control & 46.3 & 41.5 & 7.3 & 2.4 & 2.4 & 61.0 & 39.0 \\
\hline & & Case & 25.0 & 25.0 & 14.3 & 28.6 & 7.1 & 21.4 & 78.6 \\
\hline & \multirow{2}{*}{ Fat } & Control & 45.5 & 27.3 & 18.2 & 0.0 & 9.1 & 81.8 & 18.2 \\
\hline & & Case & 18.8 & 31.2 & 18.8 & 0.0 & 31.2 & 31.2 & 68.8 \\
\hline
\end{tabular}




\section{Discussion}

In this study we aimed to investigate the frequency of depression and sleep disorder and their effect on diabetic patients in comparison with nondiabetics.

Our study showed higher prevalence of depression in diabetic patients than non- diabetics. The rate of depression in patients was $78.1 \%$, and in nondiabetic group was $50 \%$. In this regard, a study that conducted by Noroozinejad et al. (12) in 2003 on 309 diabetic patients in Golestan hospital, Ahwaz, Iran. To compare the rate of depression in diabetic patients with non -diabetics, in which the frequency of depression in the diabetic group (72.2\%) was higher than Nondiabetic group $(37 \%)$.

In our study, the prevalence of depression in both sexes in diabetic patients is more than control group. The prevalence of depression in diabetic women was $82.9 \%$ and in diabetic men was $72.4 \%$. It didn't considered in other studies, so there is no evidence to prove or disprove it.

We found that the frequency of depression does not correlate with the duration of disease. In a crosssectional study that was done by Mousavi et al. (13) in 2007 in Shahrood, Iran. 100 diabetic patients were observed. He concluded that there was no significant relation between the duration of diabetes and depression. But in another study, in 2008 in Yazd, Iran. Mazlomi et al. (14) reported a significant relation between duration of diabetes and depression. Taziki et al. (15) in 2001 investigate the association of symptoms of depression with diabetes and Wrap up to the same result.

In our study, the frequency of depression in diabetic patients older than 50 years is more common than non- diabetic group. Taziki et al. (15), Mazlomi et al. (14) and Ranjbar et al. (16) in their studies revealed that with increasing age, the rate of depression among diabetic patients increased significantly. Also, in our study, there was no significant relation between the prevalence of depression and type of treatment. In 2003, in Shiraz, Iran. Ranjbar et al. (16) aimed to compare the incidence and severity of depression in adult diabetic patients who took pills and insulin and finally achieved that there is no significant relation between type of treatment and depression that we also achieved the same outcome. These results suggest that the type of blood glucose regulator does not effect on depression. But this is contrary to the achievements of the study that conducted by SepehrManesh et al. (17) in 2001 in Kashan, Iran, also Noroozinejad et al. (12) concluded that depression had been more common in patients who use insulin. The difference in the results of studies may be due to differences in the participants.

Our study did not show a significant relation between the frequency of depression and blood glucose control. In a study that conducted by Parham et al. (18) in 2013 in Qom, Iran, and also a study that was done by Nejati safa et al. (19) in 2007 in Tehran, Iran, it was concluded that there is no significant relation between blood glucose control and depression. But Richardson et al. (20) designed a retrospective study to investigate the effects of depression on glycemic control in patients with type 2 diabetes. He showed that the rate of FBS in depressed diabetic patients was higher than nondepressed diabetics. The differences in results could be due to the differences in methods, he has been examined blood glucose levels in patients who used insulin. The cause of higher symptoms of depression in patients can be related to the psychological effects of using an invasive method, such as insulin injections or prolonged duration of the disease.

Our findings indicate that the prevalence of depression in diabetic and overweight individuals is higher than non- diabetics. According to recent study that was done by Ell et al. (21) in 2015 in America. The prevalence of depression in obese diabetic people is higher than non- diabetics. This finding is similar to our results.

In our study, the prevalence of sleep disorder in diabetic patients was higher than non-diabetic group. Hemmati et al. (22) in 2012 designed a study on 180 patients and Merasi et al. (23) in 2001 that performed a case-control study on 834 patients. He considered that Sleep disorder was more common in diabetics than nondiabetic subjects that is similar to our study.

Our study showed that sleep disorder frequency in type 2 diabetic patients is not affected by the duration of the disease. In a study conducted by Ozturk et al. (24) in 2014 in Turkey, 154 patients were diagnosed. He found that there was a positive relation between the frequency of sleep disorder and the duration of diabetes that is similar to our results.

Our study did not show a positive relation between the control of blood glucose and the frequency of sleep disorder. Also parallel to our findings, Merasi et al. (23) found no relation between FBS level and sleep disorder, but there was a significant relationship between the increase in HbAlc levels and the increase in sleep disorder in his study.

In a study that conducted by $\mathrm{Yi}$ Wen et al. (25) in 2011 in the United States. There was a direct relation between FBS increase and sleep disorder in patients. In a study conducted by Tsai et al. (2) in Taiwan in 2009, the frequency of sleep disorder has a strong relation with poor blood glucose control in diabetic patients. According to the differences in results of studies about the relation between the blood glucose control and sleep disorder in diabetic patients. Perhaps more comprehensive studies can provide more accurate information on the effect of blood glucose control and sleep disorder.

Our study showed that the frequency of sleep disorder in type II diabetic patients is not affected by the type of treatment. In the study that conducted by Ford et al. (26) There was no significant difference between the sleep disorder and type of treatment that is similar to our results.

In our study the frequency of sleep disorder was significantly higher in diabetic women than nondiabetics. Similar to our study, Merasi et al. (23), Showed that the frequency of sleep disorder in diabetic women is higher.

The frequency of sleep disorder in diabetic patients with overweight and obesity was significantly 
higher than non-diabetics. But in the study that performed by Merasi et al. (23), there was no significant relation between BMI and sleep status among diabetic patients.

\section{Limitations}

In this study, laboratory criteria were not measured by the same labs.

It is recommended that studies be conducted with a larger sample size.

It is suggested that a prospective cohort study is conducted to investigate the relation between the duration of diabetes and the type of treatment with the frequency of depression and sleep disorder in order to obtain more accurate and reliable results.

\section{Conclusion}

The results of this study showed that the frequency of depression and sleep disorder in diabetic patients was higher than non-diabetic subjects. Which indicates the importance of paying attention to sleep hygiene and the individual's psychological state, especially in terms of depression, the patient's training, relaxation techniques, screening and timely referral to a psychiatrist or psychologist.

\section{References}

1. Azimi-Nezhad M, Ghayour-Mobarhan M, Parizadeh M $\mathrm{R}$, Safarian $\mathrm{M}$, et al. Prevalence of type 2 diabetes mellitus in Iran and its relationship with gender, urbanisation, education, marital status and occupation. Singapore Med J. 2008; 49(7); 571.

2. Tsai YW, Kann NH, Tung TH, Chao YJ, Lin CJ, Chang $\mathrm{KC}$, Chang SS, Chen JY. Impact of subjective sleep quality on glycemic control in type 2 diabetes mellitus. Fam Pract. Feb 2012; 29(1); 30-5.

3. Bent S, Padula A, Moore D, Patterson M, Mehling W. Valerianfor sleep: a systematic review andmeta-analysis. Am J Med. 2006; 119(12).

4. Taibi DM, Landis CA, Petry H, Vitiello MV. A systematicreview of valerian as a sleep aid: safe but not effective. Sleep MedRev. Jun 2007; 11(3); 209-230.

5. Yingxiang Song, Xiao Ye, Leqin Ye, Bijun Li, Lijun Wang, Yanyin Hua. Disturbed Subjective Sleep in Chinese Females with Type 2 Diabetes on Insulin Therapy. PLoS One. 2013; 8(1); e54951.

6. Sridhar GR, Madhu K. Prevalence of sleep disturbances in diabetes mellitus. Diabetes Res Clin Pract.1994; 23(3).

7. Har M, Aghaie, Abedi, Attari A. Admission-Based Treatment Approval and Therapeutic Commitment on Depression in Patients with Type 2 Diabetes. Journal of Behavioral Sciences Research 2013; 11.2

8. Khamseh ME, Baradaran HR, Rajabali H. Depression and diabetes in Iranian patients: acomparative study. 2007; 37(1).

9. Luca A, Luca M, Calandra C. Sleep disorders and depression: brief review of the literature, case report, and nonpharmacologic interventions for depression. Clin Interv Aging. 2013; 8; 1033-1040.

10. Reynolds GJ, Monk CF, Berman TH, Kupfer DJ. The Pittsburgh Sleep Quality Index: A new instrument for psychiatric practice and research. Journal of Psychiatric
Research. 1989; 28(2); 193-213.

11. Hamilton Depression Rating Scale (HAMD)..2010 Available at: www.serene.me.uk - Hamilton Depression Rating Scale (HAM-D) .accessed on: jan 20, 2014.

12. Noroozinejad, Boostani GH, Nematpur H. Comparison of Depression in Diabetic Patients and Non-diabetics. Scientific Journal of Medicine. 2006; 5 (2)

13. Mousavi E, gentlemen, Razavian Zadeh N, Nurvizi N, Khosravi A. Depression and general health in type 2 diabetic patients. Knowledge and health education. 1387; $3(1) ; 44-48$

14. Mazlomi S, Mirza'i A, Mohammadi S, Prevalence of depression in type 2 diabetic patients referring to Yazd diabetes research center in 2008. Yazd School of Public Health, 2009; 7 (1); 30-36.

15. Taziki S, Bazrarshan H, Behnam Pour N, Mathis P. Relationship Symptoms of Depression with Diabetes. Journal of Gorgan University of Medical Sciences. 2001; $3(8) ; 59-64$.

16. Rangbar Kh, Sharif F, Dezhbakhsh T. Frequency and severity of depression in diabetic adult patients with pills and insulin. Hormozgan Journal of. 2006; 10 (4); 363369.

17. Sepehrmanesh Z, Sarmast H, Sadr F, Sarbuluki Sh. Prevalence and type of depression and its related factors in diabetic patients. Feyz Journal .1382; 7 (3).

18. Parham M, Hosseinzadeh F, Hajizadeh J, Norouzinejad. Symptoms of Depression and Blood Glucose Control in Patients with Type 2 Diabetes. 1392; 31 (256).

19. Nejati Safa, Larijani B, Shariati B, Amini H, Rezaghlizadeh. Depression. Quality of Life and Blood Glucose Control in Patients with Diabetes. 2007; 7 (2).

20. Richardson LK, Egede LE, Mueller M, Echols CL, Gebregziabher M. Longitudinal effects of depression on glycemic control in veterans with Type 2 diabetes. General Hospital Psychiatry. 2008; 30; 509-14.

21. Ell K, Katon W, Lee PJ, Guterman J, Wu S. Demographic, clinical and psychosocial factors identify a high-risk group for depression screening among predominantly Hispanic patients with Type 2 diabetes in safety net care. General Hospital Psychiatry.2015; 8343 (15); $135-138$.

22. Hemati Z, Alidosti M, Rysiyi M.Comparison of sleep quality of type 1 diabetic patients with non-diabetic subjects. Journal of Pediatrics, 2011; 11 (6); 863-867.

23. Merati M, Amini M, Khair Abadi, Fakhari Esfarayeni, Zanari Yazdi. Comparison of nightly sleep in patients with type 2 diabetes, impaired glucose tolerance or fasting blood glucose with non-diabetic subjects. Journal of Endocrinology and Metabolism of Iran. 1390; 13 (2); 172 $-165$

24. Öztürk ZA, Yesil Y, Kuyumcu ME, Savas E, UygunÖ, Sayıner Z, Kepekçi Y .Association of depression and sleep quality with complications of type 2 diabetes in geriatric patients.Aging Clinical and Experimental Research.2015; 27(4); 533-538.

25. Yi-Wen T, Nai-Hsuan K. Impact of subjective sleep quality on glycemic control in type 2 diabetes mellitus. Family Practice 2011; 4; 1-6

26. Ford ES, Wheaton AG, Chapman DP, Li C, Perry GS, Croft JB. Associations between self-reported sleep duration and sleeping disorder with concentrations of fasting and 2-h glucose, insulin, and glycosylated hemoglobin among adults without diagnosed diabetes. Journal of Diabetes.2014;6(4); 338-350 